\title{
Removing polycyclic aromatic hydrocarbons from water using granular activated carbon: kinetic and equilibrium adsorption studies
}

\author{
Dinushika Eeshwarasinghe, Paripurnanda Loganathan, Mahatheva Kalaruban, Danious \\ Pratheep Sounthararajah, Jaya Kandasamy, Saravanamuthu Vigneswaran*
}

Faculty of Engineering, University of Technology Sydney (UTS), P.O. Box 123, Broadway, NSW 2007, Australia

*Corresponding author. Tel.:+61295142641, fax: +61295142633.

Email:s.vigneswaran@uts.edu.au

\begin{abstract}
Polycyclic aromatic hydrocarbons (PAHs) constitute a group of highly persistent, toxic and widespread environmental micropollutants that are increasingly found in water. A study was conducted in removing five PAHs, specifically naphthalene, acenaphthylene, acenaphthene, fluorene and phenanthrene from water by adsorption on to granular activated carbon. The pseudo-first order (PFO) model satisfactorily described the kinetics of adsorption of the PAHs. The Weber and Morris diffusion model's fit to the data showed that there were faster and slower rates of intra-particle diffusion probably into the mesopores and micropores of the GAC, respectively. These rates were negatively related to the molar volumes of the PAHs. Batch equilibrium adsorption data fitted well to the Langmuir, Freundlich and Dubinin-Radushkevich models, of which the Freundlich model exhibited the best fit. The adsorption affinities were related to the hydrophobicity of the PAHs as determined by the log Kow values. Free energies of adsorption calculated from the Dubinin-Radushkevich model and the satisfactory kinetic data fitting to PFO model suggested physical adsorption of the PAHs. Adsorption of naphthalene,
\end{abstract}


acenaphthylene, acenaphthene in fixed-bed columns containing a mixture of GAC $(0.5 \mathrm{~g})+$ sand (24.5 g) was satisfactorily simulated by the Thomas model.

Keywords: polycyclic aromatic hydrocarbon, adsorption, granular activated carbon, fixed-bed column adsorption, Weber and Morris diffusion model, kinetic adsorption models, equilibrium adsorption models

\section{Introduction}

Polycyclic aromatic hydrocarbons (PAHs) are a group of organic molecules comprised of fused aromatic rings and are regarded as very toxic and carcinogenic microorganic pollutants. They are generated from natural and anthropogenic activities such as bush fires, military operations, vehicular emissions, agriculture, residential waste burning, combustion of fossil fuels, leakages from the petroleum industry, manufacturing of carbon black, coal tar pitch and asphalt, heating and power generation, and emissions from internal combustion engines (Khan et al. 2007; Lamichhane et al. 2016; Manoli and Samara 1999; Nguyen et al. 2014: Yuan et al. 2010). These activities release significant amounts of PAHs into the environment. PAHs are regarded as widespread and persistent organic compounds which can accumulate to dangerous levels in the environment over time (Makkar and Rockne 2003). To protect the environment, the World Health Organization (WHO) has recommended concentration limits for various PAHs in drinking water. Furthermore, the United States Environmental Protection Agency (USEPA) effluent guidelines division has included PAH in its list of priority pollutants for constant monitoring in industrial effluents. To this end the USEPA has categorised 16 PAHs in its priority list because they cause great damage to the environment and human health (Yakout et al. 2013; Zhang et al. 2004). 
Due to the toxic, mutagenic and carcinogenic natures of PAHs, significant interest has risen in developing appropriate processes for the removal of PAHs (Liu et al. 2016; Makkar and Rockne 2003; Yuan et al. 2010). Usually PAHs are difficult to remove efficiently when applying conventional physicochemical methods such as coagulation, flocculation, sedimentation, filtration or ozonation. However, the adsorption process has emerged as a most promising technique in the removal of persistent organic pollutants and, in particular, activated carbon (AC) adsorbents are widely used for this purpose (Chen et al. 2008; Cooney 1999; Crisafully et al. 2008 Valderrama et al. 2008). Some advantages AC possesses are as follows: large internal specific surface area and highly developed porous structure, and efficient adsorption of pollutants even at low concentrations (Ania et al. 2007). Furthermore, another benefit is that PAHs are removed by AC from the water rather than simply being broken down by oxidation or reduction to potentially more dangerous metabolites (Valderrama et al. 2008).

Extensive research has been carried out on PAHs removal using AC to remove one or two PAHs, yet only a very few studies have been conducted with a suite of PAHs (Khan et al. 2007; Valderrama et al. 2007, 2008, 2009). The majority of studies on utilising AC to remove PAHs have been conducted in static batch experiments, while only a few were done employing dynamic column experiments (Khan et al. 2007). The latter ones are more relevant to practical water treatment conditions in the field. The aims of this study, therefore, were to: (1) investigate the batch kinetic and equilibrium adsorption of five PAHs on to a granular activated carbon (GAC) and to explain the adsorption processes by using mathematical models; and (2) investigate the adsorption of three PAHs on to GAC using dynamic fixed-bed column experiments and model the breakthrough curves using the Thomas model. The concentrations of PAHs used were similar to those of highly polluted industrial effluents and therefore, the results can be applied to treatment of these effluents. 


\section{Material and methods}

\section{Materials}

Granular activated carbon used in the study was obtained from James Cummins P/L, Australia. It had a nominal size of $0.3-2.4 \mathrm{~mm}$. To reduce the experimental variability, a narrow particle size range of 0.6-1 mm GAC was selected for the study. PAHs employed in the adsorption experiments were naphthalene, acenaphthylene, acenaphthene, fluorene and phenanthrene. The characteristics of the PAHs are presented in Table 1. Since PAHs had low solubility in water, experimental solutions were prepared from concentrated stock solutions of each PAH dissolved in acetonitrile as reported by Valderrama et al. (2009). The stock solutions contained $20 \mathrm{mg}$ PAH in $40 \mathrm{~mL}$ acetonitrile $(0.5 \mathrm{~g} / \mathrm{L})$. Experimental solutions were prepared by diluting the stock solutions in $1 \%$ acetonitrile made-up with Milli- $\mathrm{Q}^{\circledR}$ water (ultra-pure water) for batch experiments and tap water for column experiments. To achieve the $6 \mathrm{mg} / \mathrm{L}$ used in the adsorption experiments, $13 \mathrm{~mL}$ stock solutions were diluted to $1 \mathrm{~L}$ using $1 \%$ acetonitrile for naphthalene, acenaphthylene, acenaphthene. The acetonitrile concentration in the final solution was $2.3 \%$ for these PAHs. As fluorene and phenanthrene did not dissolve in the $1 \%$ acetonitrile, additional undiluted acetonitrile was added to the experimental solutions until they dissolved. The final acetonitrile concentration for fluorene and phenanthrene was $4.5 \%$. Acetonitrile and PAHs used were spectroscopic grade materials purchased from Sigma-Aldrich.

\section{GAC characteristics}

Surface morphology of GAC particles was examined using a Hitachi S3400 Scanning Electron Microscope operated at $20 \mathrm{kV}$. Samples were sputter coated with gold prior to analysis. Surface 
area and porosity characteristics were measured using nitrogen adsorption-desorption isotherm by employing a Micrometrics TriStar 3000 Analyser (Micromeritics Instrument Co, USA). The specific surface area was determined using the nitrogen isotherm data measured at $77 \mathrm{~K}$ from a relative pressure $\left(\mathrm{p} / \mathrm{p}_{\mathrm{o}}\right)$ of $10^{-5}$ to 0.99 by applying the BET equation. Before the analysis, the sample was vacuum dried for $3 \mathrm{~h}$ at $150{ }^{\circ} \mathrm{C}$. The total pore volume was estimated to be the liquid volume of nitrogen at a relative pressure of 0.99 . The micropore pore volume and the mesopore pore volume were calculated from the $\mathrm{N}_{2}$ isotherms data by Dubinin-Astakov (DA) and BJH methods, respectively (Long et al. 2008; Sing 2004). The algorithm used in the TriStar 3000 Analyser is an implementation of these methods. Pore-size distributions were calculated by applying the density functional theory (DFT) to the $\mathrm{N}_{2}$ isotherm data using the Micromeritics Software of the analyser (Long et al. 2008; Sing 2004). 
Table 1. Characteristics of the PAHs used in the study ${ }^{1}$

\begin{tabular}{|c|c|c|c|c|c|c|c|}
\hline PAH & $\begin{array}{l}\text { Molecular } \\
\text { formula }\end{array}$ & $\begin{array}{l}\text { Molecular } \\
\text { structure }\end{array}$ & $\begin{array}{l}\text { Molecular } \\
\text { weight } \\
(\mathrm{g} / \mathrm{mol})\end{array}$ & $\begin{array}{l}\text { Aqueous } \\
\text { solubility } \\
\left(25^{0} \mathrm{C}\right) \\
(\mathrm{mg} / \mathrm{L})\end{array}$ & $\begin{array}{l}\text { Log } \\
\mathrm{K}_{\mathrm{ow}}\end{array}$ & $\begin{array}{l}\text { Molar } \\
\text { volume } \\
\left(\mathrm{cm}^{3} / \mathrm{mol}\right)\end{array}$ & $\begin{array}{l}\text { Molar } \\
\text { dimensions } 1,3 \\
(\AA ̊))^{*}\end{array}$ \\
\hline Naphthalene & $\mathrm{C}_{10} \mathrm{H}_{8}$ & (0) & 128 & 31.7 & 3.30 & 148 & $9.1 * 7.3 * 3.8$ \\
\hline Acenaphthylene & $\mathrm{C}_{12} \mathrm{H}_{8}$ & & 152 & 16.1 & 3.94 & $168^{*}$ & - \\
\hline Acenaphthene & $\mathrm{C}_{12} \mathrm{H}_{10}$ & & 154 & 3.9 & 3.92 & 173 & $9.1 * 8.3 * 4.2$ \\
\hline Fluorene & $\mathrm{C}_{13} \mathrm{H}_{10}$ & (0) & 166 & 1.9 & 4.18 & 188 & $11.4 * 7.3 * 4.2$ \\
\hline Phenanthrene & $\mathrm{C}_{14} \mathrm{H}_{10}$ & & 178 & 1.15 & 4.46 & 199 & $11.6 * 7.9 * 3.8$ \\
\hline
\end{tabular}

${ }^{1}$ Awoyemi (2011); ${ }^{2}$ Miller et al. (1985); ${ }^{3}$ Wammer and Peters (2006). ${ }^{*}$ This value was estimated from Fig. 3 and Table 2 in the paper by Gustafson and Dickhut (1994). * $1 \AA=0.1 \mathrm{~nm}$.

\section{PAH analysis}

All experiments were conducted on the five PAHs individually. PAH concentration in the solution was determined using UV-VIS Spectrophotometry (SHIMADZU UV-1700). The absorbance values of PAHs were determined at the following wavelengths: naphthalene, 219 $\mathrm{nm}$; acenaphthene, $226 \mathrm{~nm}$; acenaphthylene, $228 \mathrm{~nm}$; fluorene, $263 \mathrm{~nm}$; and phenanthrene, 250 $\mathrm{nm}$. These wavelengths were found to be the optimum values for measuring the concentrations of the PAHs in our earlier study (Eeshwarasinghe et al. 2017). PAHs concentrations were 
determined from standard curves of absorption vs concentrations of the standards. All glassware used in this study were specially cleaned to minimise the risk of contamination. Glassware were washed and rinsed with organic-free, deionised water and then soaked overnight in a 1: $1 \mathrm{HNO}$ acid bath before use. Losses caused by photodegradation were minimised by covering all containers used to hold the PAH solutions with aluminium foil. To prevent volatilisation losses of PAH, all the containers were tightly closed by sealing them.

\section{Batch kinetic adsorption experiments}

Kinetic adsorption experiments were conducted utilising a set of glass flasks with $25 \mathrm{mg}$ of GAC in $70 \mathrm{~mL}$ of solutions containing $6 \mathrm{mg} / \mathrm{L}$ of naphthalene, acenaphthene, acenaphthylene, fluorene or phenanthrene. The suspensions were agitated in a flat shaker at a shaking speed of $120 \mathrm{rpm}$ for $24 \mathrm{~h}$. Samples were taken at different time intervals periodically commencing at 5

min up to $24 \mathrm{~h}$. The samples were filtered using glass fibre membrane filters with $1.2 \mu \mathrm{m}$ openings and the filtrates were analysed for the PAHs. PAH solutions without GAC were included as controls to account for the losses of PAH resulting from activities other than adsorption onto GAC such as volatilisation losses and adsorption on to glassware (Khan et al. 2007). All adsorption experiments were conducted at $24 \pm 1{ }^{\circ} \mathrm{C}$. The experiments were duplicated and the average values were taken for data analysis. The adsorption data were modelled using the pseudo-first order (PFO), pseudo-second order (PSO) and Elovich models (Table 2). The amount of PAH adsorbed ( $\left.\mathrm{q}_{\mathrm{t}}\right)$ at time $\mathrm{t}$ was calculated using equation (1).

$$
q_{t}=\frac{\left(C_{0}-C_{t}\right) V}{M}
$$


where $\mathrm{C}_{0}$ is initial concentration of PAH $(\mathrm{mg} / \mathrm{L}), \mathrm{C}_{t}$ is concentration of PAH at time $\mathrm{t}(\mathrm{mg} / \mathrm{L})$, $\mathrm{V}$ is volume of the solution (L) and $\mathrm{M}$ is mass of dry adsorbent $(\mathrm{g})$.

\section{Batch equilibrium adsorption experiments}

To $70 \mathrm{~mL}$ of acetonitrile-water solution containing PAHs at a concentration of $6 \mathrm{mg} / \mathrm{L}$ in a set of glass flasks, different weights of GAC $(0.6-0.8 \mathrm{~mm})$ were added to provide GAC dosages of 2-50 mg/L. The flasks were agitated in a shaker at $120 \mathrm{rpm}$ for $6-8 \mathrm{~h}$ at $24 \pm 1{ }^{\circ} \mathrm{C}$. This period of shaking was sufficient enough for the adsorption to reach equilibrium. Similarly, control samples without GAC were included and conducted. The experiments were duplicated and the average values were taken for data analysis. Once the equilibrium was attained, PAHs concentrations and amounts of PAHs adsorbed were determined as in the kinetics experiments. The data were modelled using the Langmuir, Freundlich and Dubinin-Radushkevich adsorption isotherm models (Table 2). The amounts of PAHs adsorption at equilibrium, $\mathrm{q}_{\mathrm{e}}(\mathrm{mg} / \mathrm{g})$ were calculated using the equation given below (equation 2):

$q_{e}=\frac{\left(C_{0}-C_{e}\right) \cdot V}{M}$

where $\mathrm{C}_{0}$ is initial concentration of PAH $(\mathrm{mg} / \mathrm{L}), \mathrm{C}_{\mathrm{e}}$ is equilibrium concentration of PAHs $(\mathrm{mg} / \mathrm{L}), \mathrm{V}$ is volume of solution $(\mathrm{L})$ and $\mathrm{M}$ is mass of adsorbent $(\mathrm{g})$. Percentage adsorption was calculated using equation 3 as follows:

Percentage adsorption $(\%)=\frac{\left(C_{0}-C_{e}\right)}{C_{0}} * 100$ 


\section{Column adsorption experiments}

The fixed-bed column used in the study consisted of a 2-cm inner diameter Pyrex glass tube. At the bottom of the column, a stainless-steel sieve was attached followed by a layer of glass beads to provide a uniform flow of the solution through the column. Different weight ratios of sand to GAC (24.5:0.5, 23.0:2.0, 21.5:3.5, 20.0:5.0) were used to determine acenaphthylene adsorption on to GAC. GAC and sand were mixed well and packed in the column to a bed height of 7-8 cm. Acenaphthylene $(0.75 \mathrm{mg} / \mathrm{L})$ spiked tap water solutions were pumped downward through the column at a filtration velocity of $18 \mathrm{~m} / \mathrm{h}$ controlled by a peristaltic pump. Columns and tubes were closed tightly and externally covered with aluminium foils to minimise any losses that might occur due to other reasons. The effluents at the outlet of the column were collected at regular time intervals and the concentrations of acenaphthylene were measured. Similar column experiments were conducted using 25 to $30 \mathrm{~g}$ of only sand $(0.6-2 \mathrm{~mm})$ in the columns to investigate whether acenaphthylene is removed by sand alone in the column. Column experiments were also carried out using naphthalene $(0.75 \mathrm{mg} / \mathrm{L})$ and acenaphthene $(0.75 \mathrm{mg} / \mathrm{L})$ with sand to GAC ratio $24.5: 0.5$ and flow rate $18 \mathrm{~m} / \mathrm{h}$. This made it possible to compare the adsorption capacities of these PAHs on GAC.

The column experimental data were modelled using the Thomas model (Table 2). The maximum adsorption of PAH (mg) in the fixed-bed was calculated from equation 4 as stated below:

$$
q_{\text {total }}=\frac{Q}{1000} \int_{t=0}^{t-t o t a l} C_{a d} \cdot d t
$$

where $C_{a d}$ is the adsorbed PAHs concentration $\left(C_{a d}=C_{0}-C_{t}\right) m g / L$. The maximum adsorption capacity (mg/g) was calculated from Eq. (5): 
$q_{e q}=\frac{q_{\text {total }}}{M}$

where $\mathrm{M}$ is the mass of adsorbent ( $\mathrm{g}$ ) used in the fixed-bed 
Table 2. Adsorption models

Model Equation $\quad$ Model parameter

\begin{tabular}{|c|c|c|}
\hline $\mathrm{PFO}^{1}$ & $\begin{array}{l}\text { Batch kinetics } \\
\frac{d q_{t}}{d t}=k_{1}\left(q_{e}-q_{t}\right)\end{array}$ & $\begin{array}{l}\mathrm{q}_{\mathrm{e}}=\text { amount of } \mathrm{PAH} \text { adsorbed at equilibrium }(\mathrm{mg} / \mathrm{g}) \\
\mathrm{q}_{\mathrm{t}}=\text { amount of PAH adsorbed at time } \mathrm{t}(\mathrm{h}),(\mathrm{mg} / \mathrm{g}) \\
\mathrm{k}_{1}=\text { equilibrium rate constant of pseudo-first order adsorption }(1 / \mathrm{h})\end{array}$ \\
\hline $\mathrm{PSO}^{1}$ & $\frac{d q_{t}}{d t}=k_{2}\left(q_{e}-q_{t}\right)^{2}$ & $\begin{array}{l}\mathrm{k}_{2}=\text { equilibrium rate constant of pseudo-second order adsorption } \\
(\mathrm{g} / \mathrm{mg} . \mathrm{h})\end{array}$ \\
\hline Elovich $^{2}$ & $\frac{d q_{t}}{d t}=\alpha e^{-\beta q_{t}}$ & $\begin{array}{l}\alpha=\text { initial adsorption rate }(\mathrm{mg} / \mathrm{g} . \mathrm{h}), \beta=\text { related to extent of surface } \\
\text { coverage and activation energy for chemisorption }(\mathrm{g} / \mathrm{mg}), \mathrm{e}=\text { Elovich } \\
\text { equilibrium constant }(\mathrm{L} / \mathrm{mg})\end{array}$ \\
\hline $\begin{array}{l}\text { Weber and } \\
\text { Morris }^{3}\end{array}$ & $q_{t}=K_{\mathrm{p}} t^{1 / 2}+\mathrm{B}$ & $\begin{array}{l}\mathrm{k}_{\mathrm{p}}=\text { intra-particle diffusion rate constant }\left(\mathrm{mg} /\left(\mathrm{g} \cdot \mathrm{h}^{1 / 2}\right)\right), \mathrm{B}=\text { constant } \\
\text { which provides a measure of the boundary layer thickness }(\mathrm{mg} / \mathrm{g})\end{array}$ \\
\hline Langmuir $^{1}$ & $\begin{array}{l}\text { Batch equilibrium } \\
q_{e}=\frac{q_{m} K_{L} C_{e}}{1+K_{L} C_{e}}\end{array}$ & $\begin{array}{l}\mathrm{C}_{\mathrm{e}}=\text { equilibrium concentration of PAH }(\mathrm{mg} / \mathrm{L}), \mathrm{q}=\text { amount of PAH } \\
\text { adsorbed per unit mass of adsorbent }(\mathrm{mg} / \mathrm{g}), \mathrm{q}_{\mathrm{m}}=\text { maximum amount of } \\
\text { PAH adsorbed per unit mass of adsorbent }(\mathrm{mg} / \mathrm{g}), \mathrm{K}_{\mathrm{L}}=\text { Langmuir } \\
\text { constant }(\mathrm{L} / \mathrm{mg}) \text { relates the energy of adsorption }\end{array}$ \\
\hline Freundlich ${ }^{1}$ & $q_{e}=K_{f} C_{e}^{1 / n}$ & $\begin{array}{l}\mathrm{k}_{\mathrm{f}}=\text { Freundlich constant }(\mathrm{mg} / \mathrm{g})(\mathrm{L} / \mathrm{mg})^{1 / \mathrm{n}}, \mathrm{n}=\text { Freundlich constant, } q_{e}= \\
\text { the amount adsorbed per unit dosage of the adsorbent }(\mathrm{mg} / \mathrm{g})\end{array}$ \\
\hline $\begin{array}{l}\text { Dubinin- } \\
\text { Radushkevich }\end{array}$ & $\begin{array}{l}\ln \left(q_{e}\right) \\
=\ln \left(q_{m}\right)-\beta \varepsilon^{2}\end{array}$ & $\begin{array}{l}q_{m}=\text { the monolayer capacity, } \beta=\text { the activity coefficient related to mean } \\
\text { adsorption energy and } \varepsilon=\text { Palanyi potential described as: } \varepsilon=R T \ln [1+ \\
\left.\frac{1}{C_{e}}\right] \text { where } \mathrm{R}=\text { universal gas constant } 8.314(\mathrm{~J} / \mathrm{mol} . \mathrm{K}) \text {, } \\
\mathrm{T}=\text { absolute temperature }(\mathrm{K}) \text {, From the plots of } \ln \left(\mathrm{q}_{\mathrm{e}}\right) \text { versus } \varepsilon^{2} \text { the } \\
\text { values of } \beta \text { and } \mathrm{q}_{\mathrm{m}} \text { were determined }\end{array}$ \\
\hline $\begin{array}{l}\text { Thomas } \\
\text { model }^{1}\end{array}$ & $\begin{array}{l}\text { Column adsorption } \\
\ln \left(\frac{c_{0}}{c_{t}}-1\right)=\frac{k_{T h} q_{0} M}{Q}\end{array}$ & 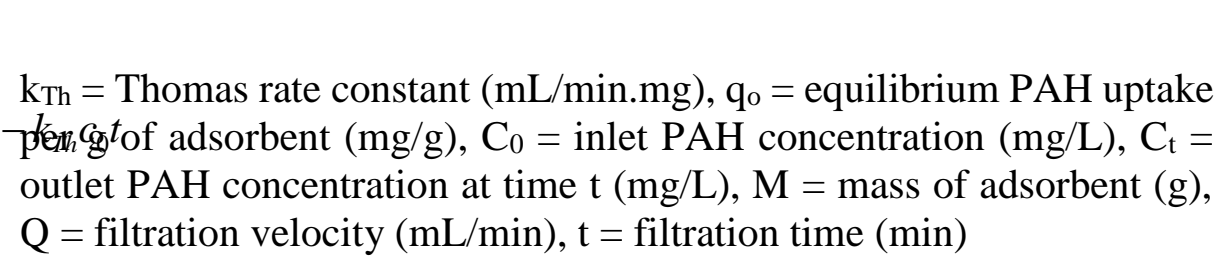 \\
\hline
\end{tabular}

${ }^{4}$ Alade et al. (2012); ${ }^{1}$ Kalaruban et al. (2016a, 2016b); ${ }^{4}$ Nguyen et al. (2015); ${ }^{1,2}$ Riahi et al.

(2017); ${ }^{3}$ Weber and Morris (1963)

\section{Results and discussion}




\section{GAC characteristics}

Some physicochemical parameters of the GAC are listed in Table 3. Fig. 1 shows the pore size distribution of GAC. Fig. 1 shows that the GAC had majority of pores between 1.8 and $15 \mathrm{~nm}$. The average pore diameter was 3.2-3.4 $\mathrm{nm}$ with micropore and mesopore volumes of $25-27 \%$ and $73-75 \%$, respectively (Table 3 ).

The scanning electron micrographs show the presence of large numbers of micropores and mesopores (Fig. 2) as indicated by the pore size distribution data (Fig. 1). Such large numbers of pores have provided the high surface area of GAC (Table 3) which is expected to produce high adsorption capacities for PAHs.

Table 3: Characteristics of GAC

\begin{tabular}{ll}
\hline Parameter/units & Value \\
\hline Nominal size $(\mathrm{mm})$ & $0.30-3.28$ \\
BET surface area $\left(\mathrm{m}^{2} / \mathrm{g}\right)$ & 0.53 \\
Total pore volume by BJH adsorption method $\left(\mathrm{cm}^{3} / \mathrm{g}\right)$ & 0.60 \\
Total pore volume by BJH desorption method $\left(\mathrm{cm}^{3} / \mathrm{g}\right)$ & 3.4 \\
Average pore diameter BJH adsorption method $(\mathrm{nm})$ & 3.2 \\
Average pore diameter BJH desorption method $(\mathrm{nm})$ & 27 \\
$\%$ micropore $(<2 \mathrm{~nm})$ volume (adsorption curve) & 25 \\
$\%$ micropore $(<2 \mathrm{~nm})$ volume (desorption curve) & 73 \\
$\%$ mesopore $(2-50 \mathrm{~nm})$ volume (adsorption curve) & 75 \\
$\%$ mesopore $(2-50 \mathrm{~nm})$ volume (desorption curve) & \\
\hline
\end{tabular}




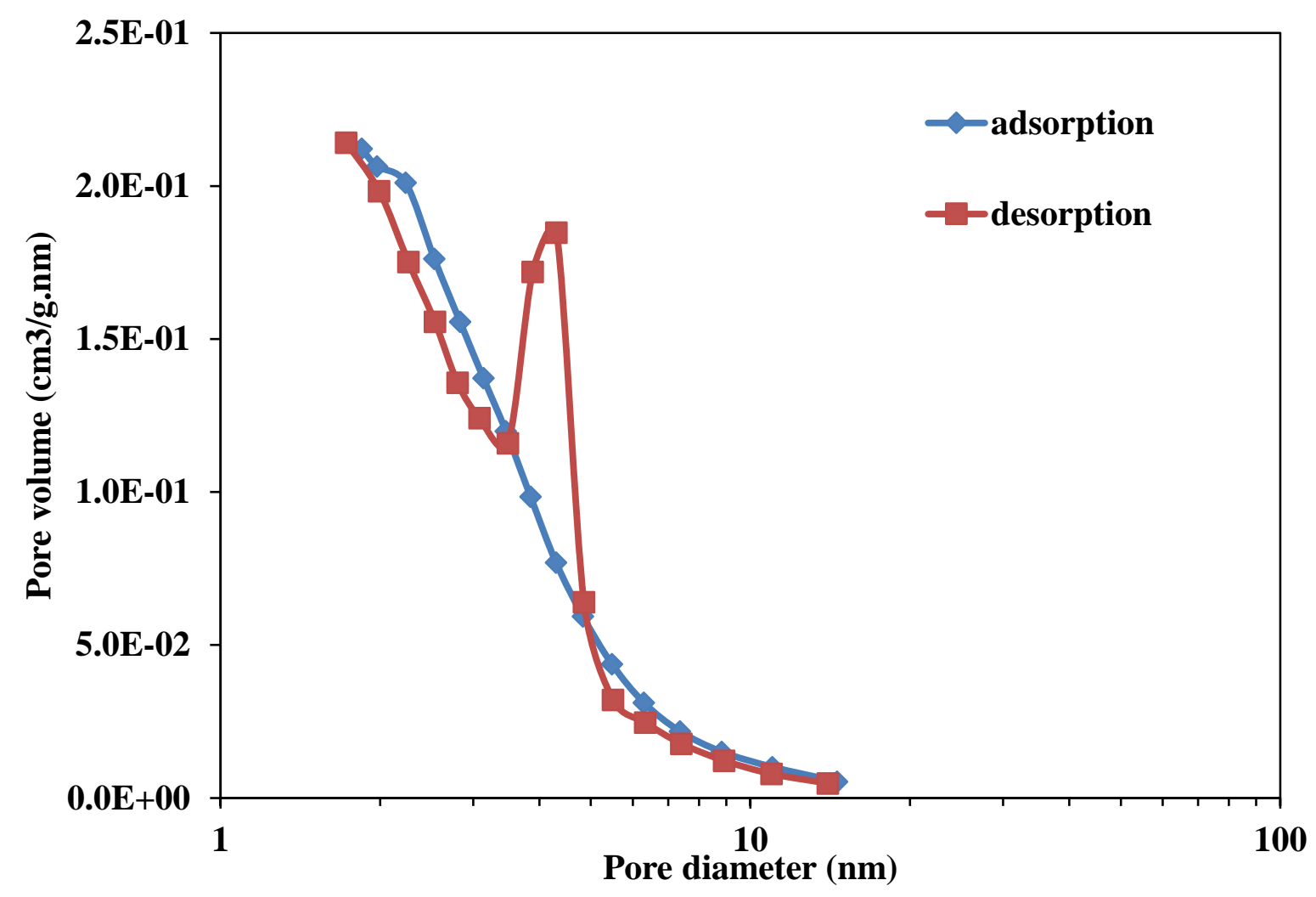

Fig. 1. Pore size distribution of GAC calculated from the $\mathbf{N}_{2}$ adsorption and desorption branches of the BJH plots. The desorption peak (hysteresis loop) at 4-6 $\mathrm{nm}$ is due to capillary condensation of $\mathrm{N}_{2}$ in the mesopores (Wu et al. 2018).
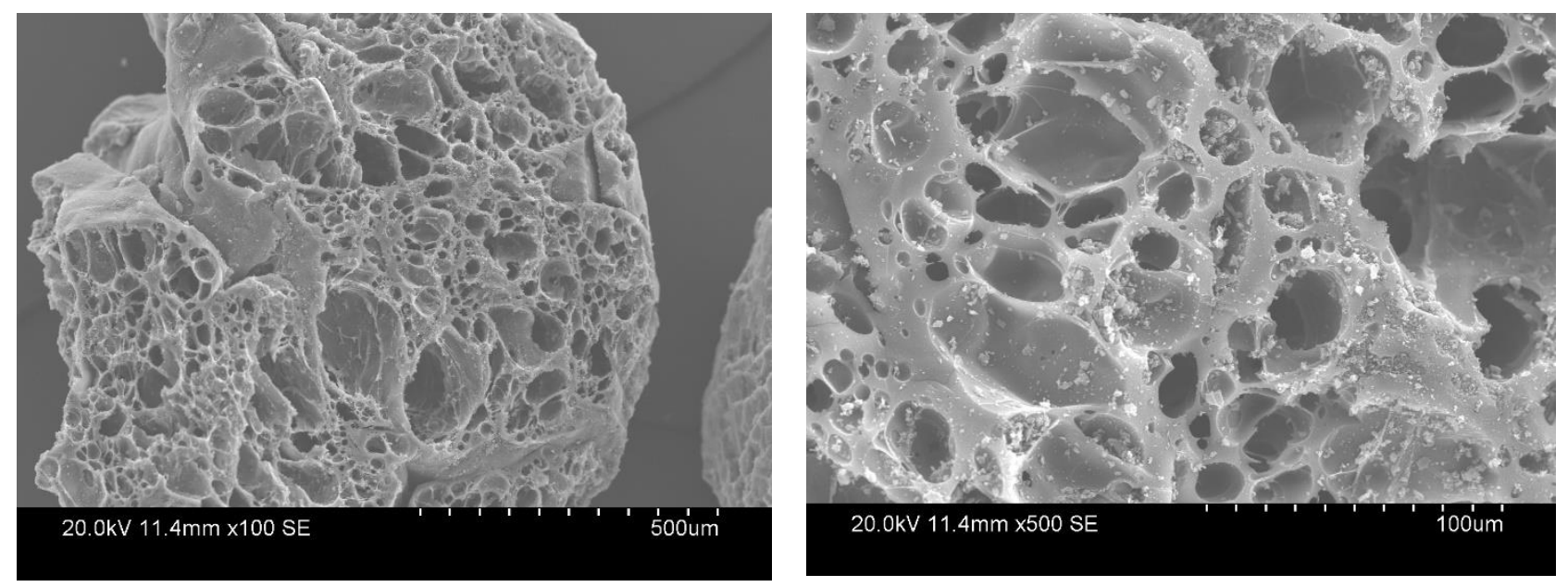

Fig. 2. Scanning electron micrographs of GAC 


\section{Kinetic adsorption experiments}

For all PAHs, the rate of adsorption was fast within the first $2 \mathrm{~h}$ (Fig. 3), probably because of adsorption on the external surface and in the larger sized mesopores of GAC. Subsequently, the rate of adsorbent progressively decreased reaching equilibrium after 4-5 h for naphthalene, 5-6 $\mathrm{h}$ for acenaphthylene, $8 \mathrm{~h}$ for acenaphthene, $16 \mathrm{~h}$ for fluorene, and $24 \mathrm{~h}$ for phenanthrene. The decline in adsorption rate over time is due to a shift in the PAH transport process from mesopores to micropores of GAC. As the molar volume of PAH increased, the penetration of PAH into the micropores became difficult. The time to reach adsorption equilibrium increased as molar volume also increased (Table 1). Naphthalene, having the lowest molar volume and molecular dimension, was able to penetrate the pores more easily than the other PAHs. The penetration of fluorene and phenanthrene having the largest molar volumes was much slower resulting in the lowest adsorption rate. Haro et al. (2011) also reported that the rate of adsorption of naphthalene on an AC was much faster than acenaphthalene and fluorene, and this was explained by the difference in their molecular dimensions. Awoyemi (2011) conducted a similar research study using naphthalene and fluorene adsorption on to an $\mathrm{AC}$ and explained the faster kinetic behaviour of naphthalene to its lower molar volume and molecular dimensions as well.

\section{Kinetic adsorption models}

Kinetic adsorption data were modelled using the PFO, PSO and Elovich models where the aim was to: firstly, determine the best model that describes the adsorption data; and secondly, understand the mechanism of adsorption (Fig. 3). Of the three models, the PFO and PSO models 
fitted the data the best with $\mathrm{R}^{2}$ values of 0.983-0.999 (Table 4). However, the model predicted values for the adsorption capacities $\left(\mathrm{q}_{\mathrm{m}}\right)$ were close to the experimental values only for the PFO model fittings. In the PSO model, the differences between experimental and model predicted values were approximately $25-30 \%$. Therefore, the PFO model is a better predictor of the adsorption kinetics than the PSO model for the PAHs. The good agreement of the data with the PFO model suggests physical adsorption of the PAHs on GAC (Awoyemi 2011; Nur et al. 2013). The mechanism of physical adsorption is probably the van der Waals attractive forces occurring between instantaneous and induced dipole moments of PAH molecules and GAC (Valderrama et al. 2009). The PFO model rate constant decreased with an increase in molar volume for the PAHs (Tables 1, 4) due to increased resistance for the diffusion of larger sized PAHs as discussed earlier. This relationship was significant with a regression equation of PFO rate constant $\mathrm{k}_{1}=-0.0039 \mathrm{x}$ molar volume +1.285 , and an $\mathrm{R}^{2}$ value of 0.7514 .

Valderrama et al. (2007) also reported that adsorption of six PAHs on a GAC was described better by the PFO model although the PSO model provided an acceptable description of the adsorption process. Long et al. (2008) reported that both the PFO and PSO models fitting to the data for the kinetics of naphthalene adsorption on an AC had correlation coefficients larger than 0.99 . Yet the estimated adsorption capacity was close to the experimental value only for the PFO model. They subsequently concluded that PFO was a better model for predicting the adsorption kinetics.

Three consecutive stages in the kinetics of adsorption process for porous adsorbents have been documented by previous researchers (Haro et al. 2011; Valderrama et al. 2008). The first stage is the migration of PAHs from the bulk solution to the GAC surface (boundary diffusion) which is very fast due to vigorous shaking of the suspensions and often cannot be measured. The main resistance to mass transfer occurs during the second stage where intraparticle diffusion due to movement of PAHs to the interior pores and channels of GAC takes place. The third stage is when adsorption reaches saturation. 
The intra-particle diffusion model developed by Weber and Morris (1963) has been used to describe the adsorption process in the second stage of PAHs adsorption (Fig.4). If the WeberMorris plot of $q_{t}$ versus $t^{1 / 2}$ gives a straight line, then the adsorption process is considered to be solely controlled by intra-particle diffusion. The data in Fig. 4 cannot be described by a single linear trend line. However, if the data is divided into zones in which different transport processes might prevail, then distinct lines can be defined and used to analyse these transport processes. The data indicates that there appears to be more than one diffusion rate for the PAHs, a faster rate followed by a slower rate as also found by Valderrama et al. (2008). The faster rate occurs in the mesopores and the slower rate in the micropores. Stage 2 of the adsorption kinetics process is divided into two zones representing the diffusion into the mesopores and micropores, respectively in Fig4. Zone 3 represents the adsorption saturation plateau. The diffusion rates, $K_{\mathrm{s} 1}$ and $K_{\mathrm{s} 2}$ calculated from the corresponding slopes of each straight line in the stage 2 process are presented in Table 5. It is obvious that the value for $K_{\mathrm{s} 1}$ is much higher than that for $K_{\mathrm{s} 2}$ for each PAH. It is interesting to note that phenanthrene has not completely reached the saturation stage within the experimental time of $24 \mathrm{~h}$ and continues to diffuse into the micropores with its very low diffusion rate of $k_{\mathrm{s} 2}=0.3 \mathrm{mg} / \mathrm{g} / \mathrm{min}^{1 / 2}$ (Table 5). This low diffusion rate is due to its large size (large molar volume, Table 1), which makes it difficult for it to penetrate into the pores. Steric hindrance might have also reduced the diffusion rate of phenanthrene (Haro et al. 2011). The diffusion rate in the mesopores $\left(K_{\mathrm{s} 1}\right)$ has a significant negative correlation with molar volume $\left(\mathrm{R}^{2}=0.60\right)$ whereas such a relationship does not exist with $K_{\mathrm{s} 2}$. The absence of a relationship for zone 2 is probably due to the gradual transition from one zone to the other which made it difficult to clearly define each zone. The demarcation of zones was not clear cut. The zones were separated by eye-estimate using the limited number of data points. 

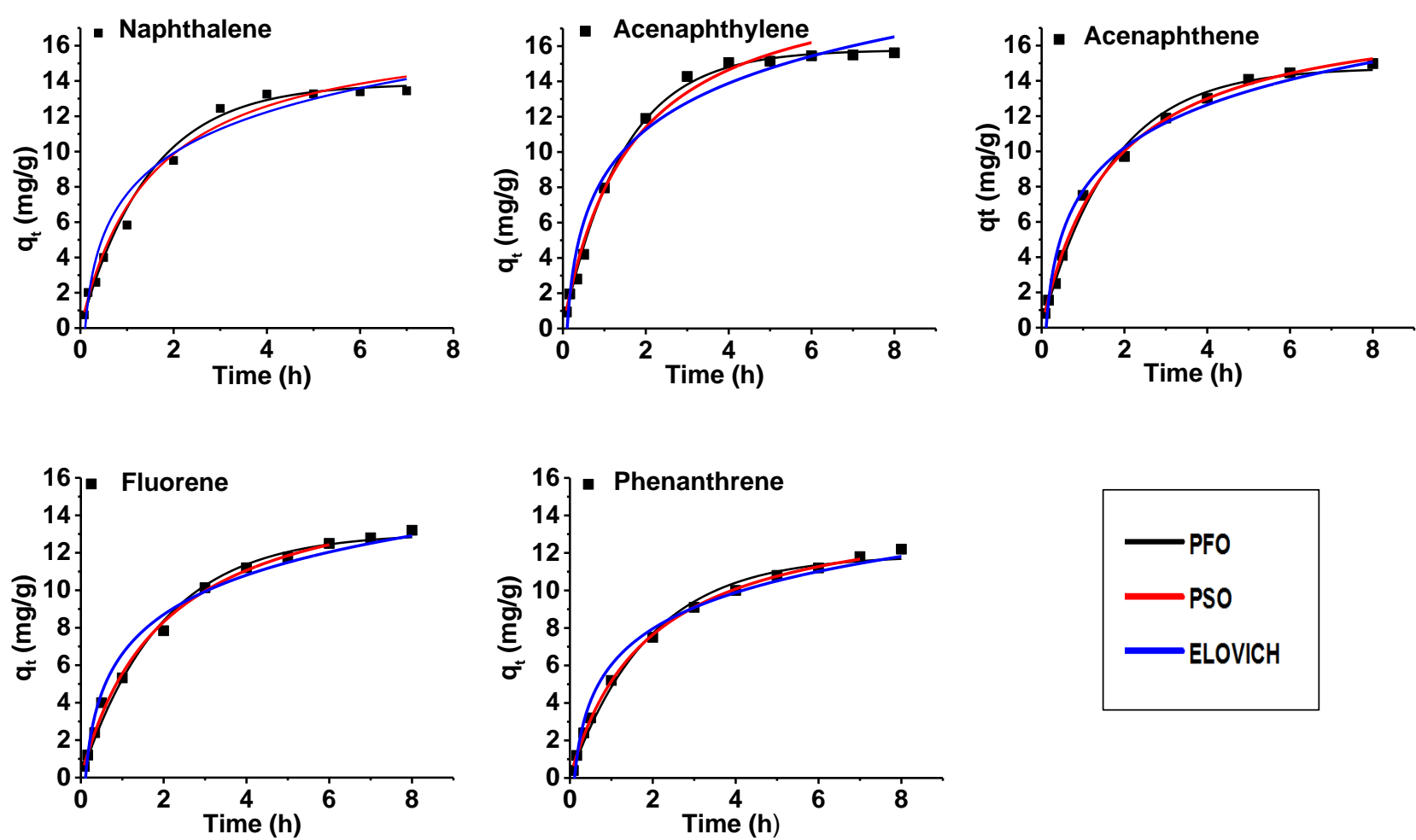

Fig. 3. Kinetics of PAHs adsorption on GAC and models' fit to the data

Table 4: Parameter values for batch kinetics adsorption models

\begin{tabular}{|c|c|c|c|c|c|c|c|c|c|c|}
\hline \multirow[t]{2}{*}{ Compound } & \multicolumn{3}{|c|}{$\begin{array}{l}\text { Pseudo-first order } \\
\text { (PFO) }\end{array}$} & \multicolumn{3}{|c|}{$\begin{array}{l}\text { Pseudo-second order } \\
\text { (PSO) }\end{array}$} & \multicolumn{3}{|l|}{ Elovich } & \multirow{2}{*}{$\begin{array}{l}\text { Experimental } \\
\mathrm{q}_{\mathrm{m}} \\
(\mathrm{mg} / \mathrm{g})\end{array}$} \\
\hline & $\begin{array}{l}\mathrm{q}_{\mathrm{m}} \\
\mathrm{mg} / \mathrm{g}\end{array}$ & $\begin{array}{l}\mathrm{k}_{1} \\
\mathrm{~h}^{-1}\end{array}$ & $\mathrm{R}^{2}$ & $\begin{array}{l}\mathrm{q}_{\mathrm{m}} \\
\mathrm{mg} / \mathrm{g}\end{array}$ & $\begin{array}{l}\mathrm{K}_{2} \\
\mathrm{~g} / \mathrm{mg} \mathrm{h}\end{array}$ & $\mathrm{R}^{2}$ & $\begin{array}{l}\alpha \\
\text { mg/g.h }\end{array}$ & $\begin{array}{l}\beta \\
\mathrm{g} / \mathrm{mg}\end{array}$ & $\mathrm{R}^{2}$ & \\
\hline Naphthalene & 13.8 & 0.68 & 0.993 & 17.3 & 0.037 & 0.983 & 2.9 & 3.3 & 0.950 & 13.4 \\
\hline Acenaphthylene & 15.7 & 0.70 & 0.997 & 20.5 & 0.030 & 0.991 & 2.5 & 3.8 & 0.963 & 15.6 \\
\hline Acenaphthene & 14.7 & 0.60 & 0.995 & 18.5 & 0.032 & 0.997 & 2.6 & 3.5 & 0.974 & 15.0 \\
\hline Fluorene & 13.0 & 0.51 & 0.993 & 16.5 & 0.031 & 0.996 & 2.9 & 3.0 & 0.974 & 13.2 \\
\hline Phenanthrene & 11.8 & 0.52 & 0.994 & 14.8 & 0.036 & 0.999 & 3.2 & 2.8 & 0.980 & 12.1 \\
\hline
\end{tabular}




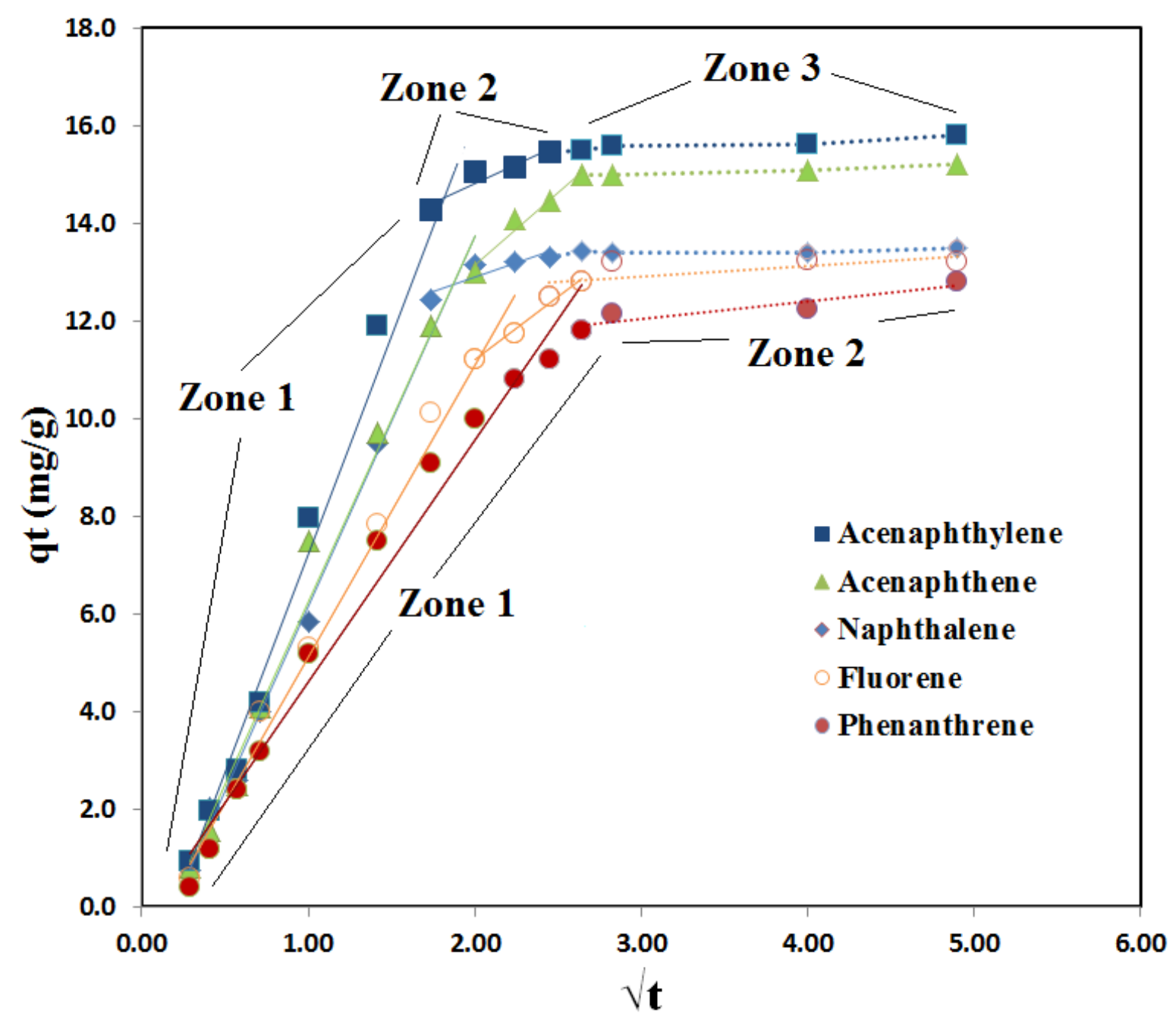

Fig. 4. Weber and Morris intra-particle diffusion plots for the adsorption of PAH on GAC 
Table 5: Diffusion rates $\left(\mathrm{k}_{\mathrm{s} 1}, \mathrm{k}_{\mathrm{s} 2}\right)$ and coefficient of determination $\left(\mathrm{R}^{2}\right)$ obtained from the Weber and Morris plots

\begin{tabular}{lllll}
\hline PAH & \multicolumn{2}{l}{ Weber-Morris short-term adsorption } & \multicolumn{2}{l}{ Weber-Morris long-term adsorption } \\
& $K_{\mathrm{s} 1}$ & $\mathrm{R}^{2}$ & $k_{\mathrm{s} 2}$ & $\mathrm{R}^{2}$ \\
& $\mathrm{mg} / \mathrm{g} / \mathrm{min}^{1 / 2}$ & & $\mathrm{mg} / \mathrm{g} / \mathrm{min}^{1 / 2}$ & \\
\hline Naphthalene & 7.6 & 0.992 & 1.0 & 0.809 \\
Acenaphthylene & 8.9 & 0.984 & 1.5 & 0.888 \\
Acenaphthene & 7.5 & 0.983 & 2.9 & 0.961 \\
Fluorene & 6.0 & 0.988 & 2.4 & 0.971 \\
Phenanthrene & 4.9 & 0.978 & 0.3 & 0.866 \\
\hline
\end{tabular}

\section{Equilibrium adsorption experiment}

The removal efficiency of PAHs by adsorption on GAC generally increased with molecular weight and molar volume of the PAHs (Fig. 5). This trend under equilibrium adsorption conditions is the reverse of that obtained under adsorption kinetics conditions discussed previously. PAHs having the lowest molar volumes exhibited the fastest adsorption rate but the total amount adsorbed at equilibrium was the lowest. The reason for this difference is that in kinetics of adsorption the larger sized PAHs resisted diffusion through the pores and channels in GAC unlike the smaller PAHs which had less resistance. At the end of a sufficient period of adsorption when equilibrium of adsorption is attained, the total amount adsorbed is related to the affinity of PAHs to GAC. This affinity is determined by the hydrophobicity of PAHs since GAC is mainly hydrophobic. In support of this reasoning, the amount of PAH adsorbed approximately followed the order of increasing $\log \mathrm{K}_{\mathrm{ow}}$ or decreasing water solubility of PAH (Table 1) as reported by others (Crisafully et al. 2008; Haro et al. 2011: Khan et al. 2007; 
Valderrama et al. 2009). It was also reported that PAHs with higher $\mathrm{K}_{\mathrm{ow}}$ had longer equilibrium time but demonstrated higher adsorption capacity (Khan et al. 2007: Haro et al. 2011).

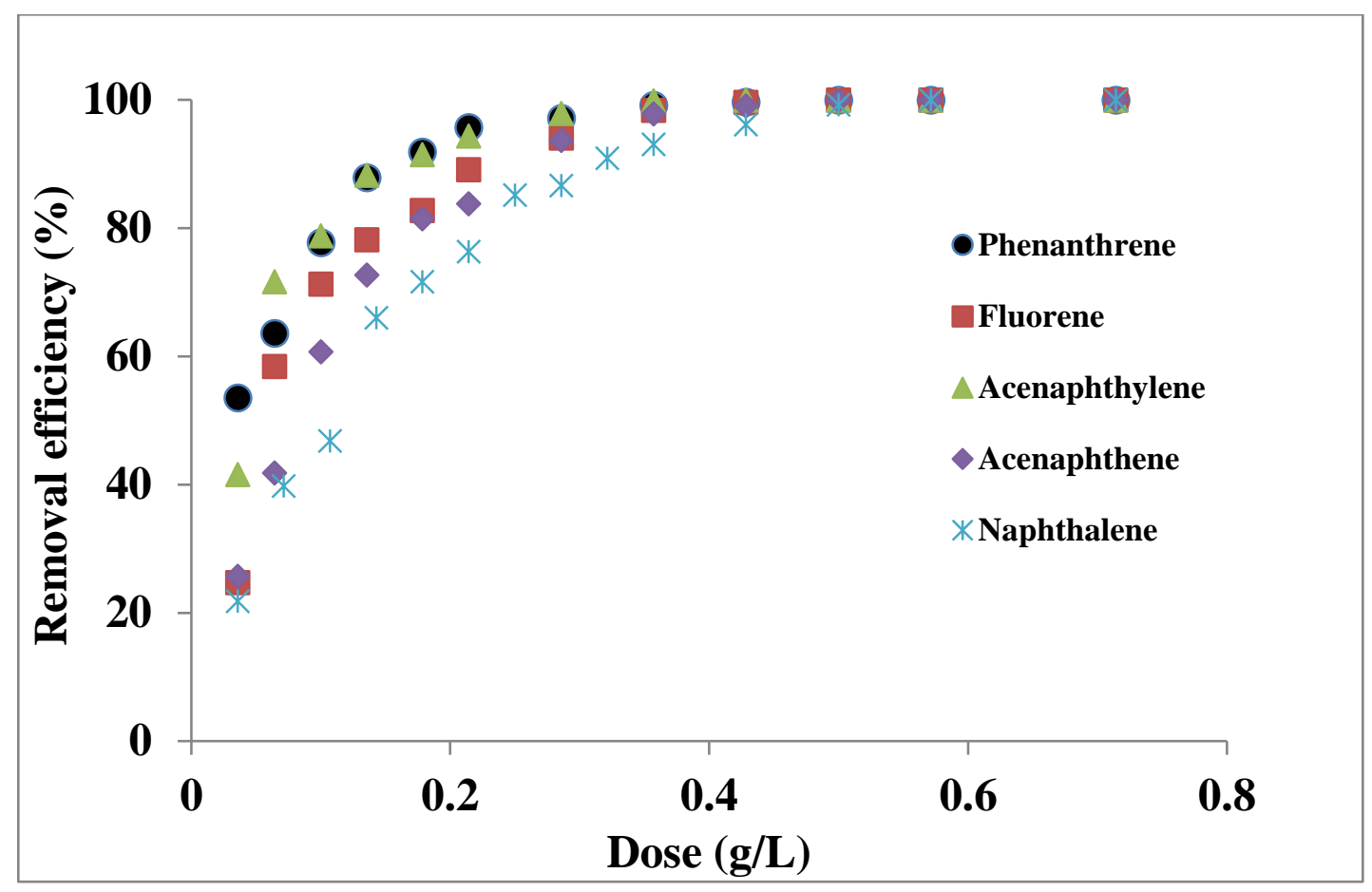

Fig. 5. Removal efficiency of PAH - batch equilibrium adsorption experiment

Adsorption equilibrium data were modelled using Langmuir, Freundlich and DubininRadushkevich isotherm models to obtain maximum adsorption capacity and affinity of adsorption of the PAHs (Fig. 6). The model parameters obtained from these fits are presented in Table 6. All three models described the adsorption data fairly well $\left(\mathrm{R}^{2}=0.801-0.992\right)$. However, the Freundlich model fitted the data most satisfactorily $\left(\mathrm{R}^{2}=0.910-0.992\right)$ indicating probably that the process is heterogeneous adsorption due to the availability of different types of pores. 

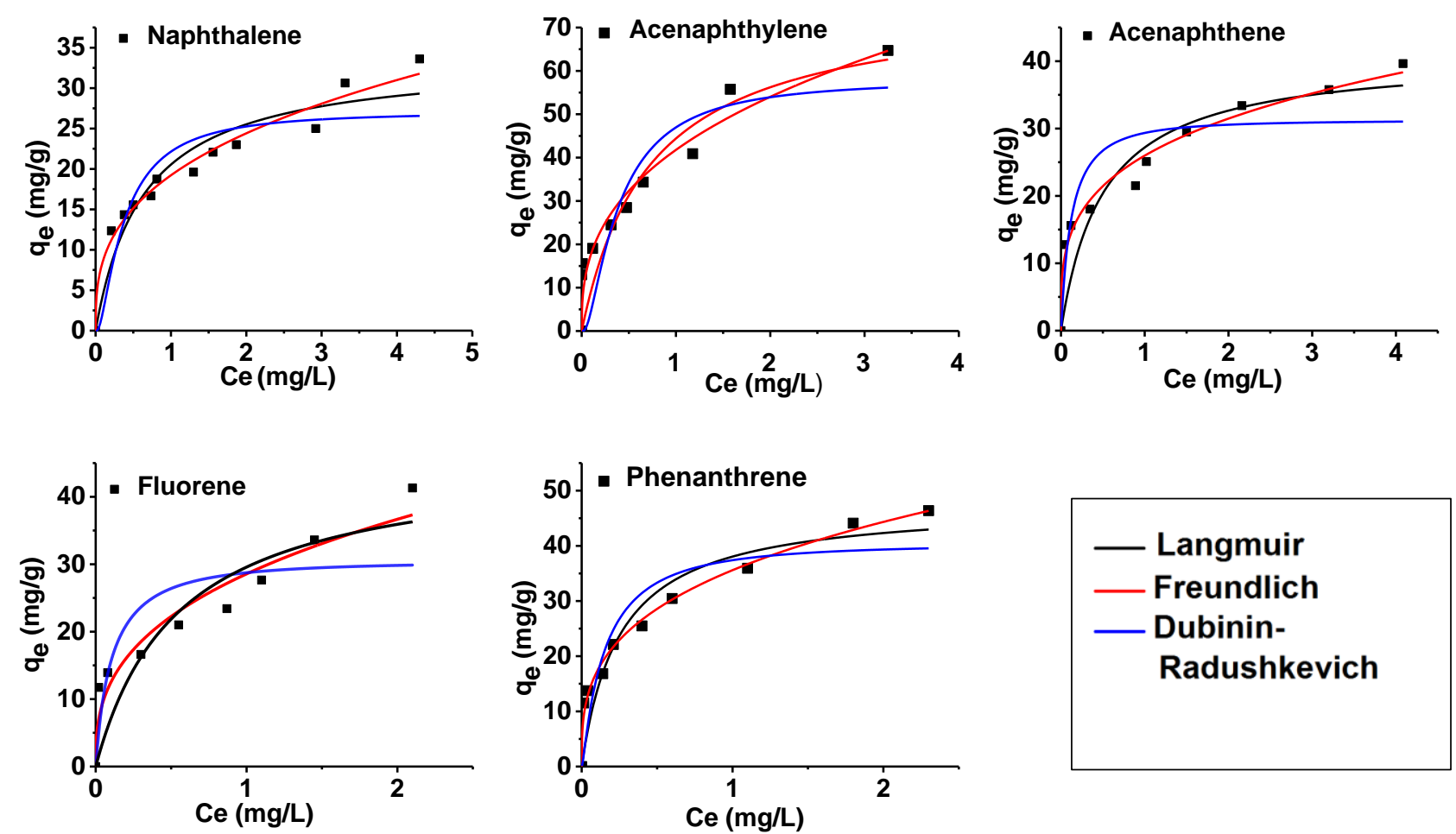

Fig. 6. Experimental data and models fit to the data of PAHs adsorption on GAC

The Langmuir maximum monolayer adsorption capacity ranged from 34 to $77 \mathrm{mg} / \mathrm{g}$. These values are lower than the values of 111,140 and $145 \mathrm{mg} / \mathrm{g}$ reported by Valderrama et al. (2009) for acenaphthene, naphthalene, and fluorene adsorption, respectively, on a GAC. They are, however, comparable to the values of 50 and $64 \mathrm{mg} / \mathrm{g}$ reported by Yakout et al. (2013) for phenanthrene and naphthalene adsorption, respectively, on an AC. Lower values compared to the values reported by Valderrama et al. (2009) may be due to using much smaller PAHs concentrations in our study $(<4 \mathrm{mg} / \mathrm{L}$ compared to values up to $100 \mathrm{mg} / \mathrm{L}$ equilibrium concentration in the study by Valderrama et al. (2009)). Yakout et al. (2013) had equilibrium concentrations similar to ours in their analysis.

The Langmuir constant related to the affinity of adsorption $\left(K_{\mathrm{L}}\right)$ increased with an increase in $\log \mathrm{K}_{\mathrm{ow}}$ as reported by others (Valderrama et al. 2009) but the relationship was not strong $\left(\mathrm{R}^{2}=0.4664\right)$. Boving and Zhang (2004) also reported a strong relationship between partition coefficient of PAHs (ratio of amount adsorbed on wood fibre and solution concentration) and $\log \mathrm{K}_{\mathrm{ow}}$ for four PAHs. These results suggest that the affinity of GAC for 
the adsorption of PAHs increases with hydrophobicity of PAHs. Thus, the adsorptive behaviour of PAHs is controlled largely by the hydrophobicity of the PAHs.

In the Langmuir model, the value of $R_{L}$ as calculated from the formula, $R_{L}=1 /\left(1+C_{m} K_{L}\right)$ (where $C_{m}$ is the maximum initial concentration of sorbate), indicates the favourability of the adsorption process, i.e. unfavourable $\left(R_{L}>1\right)$, favourable $\left(0<R_{L}<1\right)$ or irreversible $\left(R_{L}=0\right)$ (Naidu et al. 2016). The calculated $R_{L}$ values for PAHs in the current study were in the $0.10-0.21$ range (Table 6), indicating that the adsorption process is favourable for all tested PAHs. Similarly, the values of the Freundlich constant $1 / n$ were between 0.1 and 1, indicating a favourable adsorption and implying a stronger interaction between the GAC and PAHs (Yakout et al. 2013). The adsorption capacities obtained from the Dubinin-Radushkevich model for the PAHs generally followed the same order as the Langmuir adsorption capacities (Table 6). However, the magnitude of the values was approximately 10$30 \%$ lower than the Langmuir adsorption capacity values. The Dubinin-Radushkevich model has the advantage of differentiating physical adsorption and chemical adsorption using the mean free energy of adsorption $(\mathrm{kJ} / \mathrm{mol})$ which is calculated as the reciprocal of the square root of $2 \beta$. The mean free energy of adsorption $(E)$ is defined as the free energy change when one mole of adsorbate is transferred to the surface of the solid from infinity in solution (Nemr et al. 2009; Tripathy and Raichur 2008). From the magnitude of $E$, the type of adsorption such as chemisorption or physical sorption can be determined. If $E=8-16 \mathrm{~kJ} / \mathrm{mol}$, then the reaction is due to chemical adsorption; If $E<8 \mathrm{~kJ} / \mathrm{mol}$, then physical adsorption takes place (Tripathy and Raichur 2008). Values of $E$ calculated for the five PAHs tested varied from 2.0 to 3.8 (kJ/mol) (Table 6), which showed that the type of adsorption involved in this study was mainly physical adsorption. This is consistent with the adsorption kinetics study which showed PFO was the best predictive model of the data, indicating that the adsorption mechanism was mainly a physical process. 
Table 6: Parameter values for batch equilibrium adsorption models

\begin{tabular}{|c|c|c|c|c|c|c|c|c|c|c|c|c|}
\hline \multirow[t]{3}{*}{$\mathrm{PAH}$} & \multicolumn{3}{|c|}{ Langmuir model } & \multicolumn{4}{|c|}{ Freundlich model } & \multicolumn{5}{|c|}{ Dubinin-Radushkevich model } \\
\hline & $\mathrm{q}_{\mathrm{m}}$ & $K_{\mathrm{L}}$ & $\mathrm{R}^{2}$ & $\mathrm{R}_{\mathrm{L}}$ & $\mathrm{K}_{\mathrm{f}}$ & $\mathrm{N}$ & $1 / \mathrm{n}$ & $\mathrm{R}^{2}$ & $\mathrm{q}_{\mathrm{m}}$ & $\beta$ & $\mathrm{R}^{2}$ & $E$ \\
\hline & $\mathrm{mg} / \mathrm{g}$ & $\mathrm{L} / \mathrm{mg}$ & & & $(\mathrm{mg} / \xi$ & & & & $\mathrm{mg} / \mathrm{g}$ & $\left(\mathrm{mol}^{2} / \mathrm{kJ}^{2}\right)$ & & $(\mathrm{kJ} / \mathrm{mol})$ \\
\hline Naphthalene & 33.7 & 1.6 & 0.918 & 0.13 & 19.2 & 2.9 & 0.34 & 0.977 & 23.6 & 0.05 & 0.894 & 3.0 \\
\hline Acenaphthylene & 76.6 & 1.4 & 0.852 & 0.18 & 41.8 & 2.7 & 0.37 & 0.910 & 56.8 & 0.08 & 0.872 & 2.6 \\
\hline Acenaphthene & 40.8 & 1.9 & 0.881 & 0.11 & 26.0 & 3.6 & 0.28 & 0.977 & 35.5 & 0.13 & 0.994 & 2.0 \\
\hline Fluorene & 45.7 & 1.8 & 0.813 & 0.21 & 28.6 & 2.8 & 0.36 & 0.941 & 33.1 & 0.06 & 0.801 & 2.9 \\
\hline Phenanthrene & 47.6 & 4.0 & 0.908 & 0.10 & 35.6 & 3.2 & 0.31 & 0.992 & 40.4 & 0.04 & 0.917 & 3.8 \\
\hline
\end{tabular}




\section{Column experiments}

The dynamic column operation makes it possible to utilise the GAC adsorptive capacity more efficiently than the static batch process. It is also more relevant to real operating systems on natural waters. The rational design of an adsorption system is therefore based on the accurate predictions of breakthrough curves for specified conditions. Using GAC alone in a largescale process in a treatment plant is a costly exercise. Mixing it with appropriate proportions of inert coarse-sized materials like sand may reduce the operation costs without compromising PAH removal efficiency too much. Mixing with sand also provides good hydraulic properties in the fixed-bed column adsorption process. Therefore, dynamic fixedbed adsorption column experiments were conducted using GAC + sand mixtures for the removal of PAHs. To evaluate the contribution of sand in the mixture to PAH adsorption, a column experiment was initially conducted using only sand. The breakthrough curves for the adsorption of acenaphthylene on sand at two filter velocities showed that sand had negligible adsorption capacity for acenaphthylene (Fig. 7).

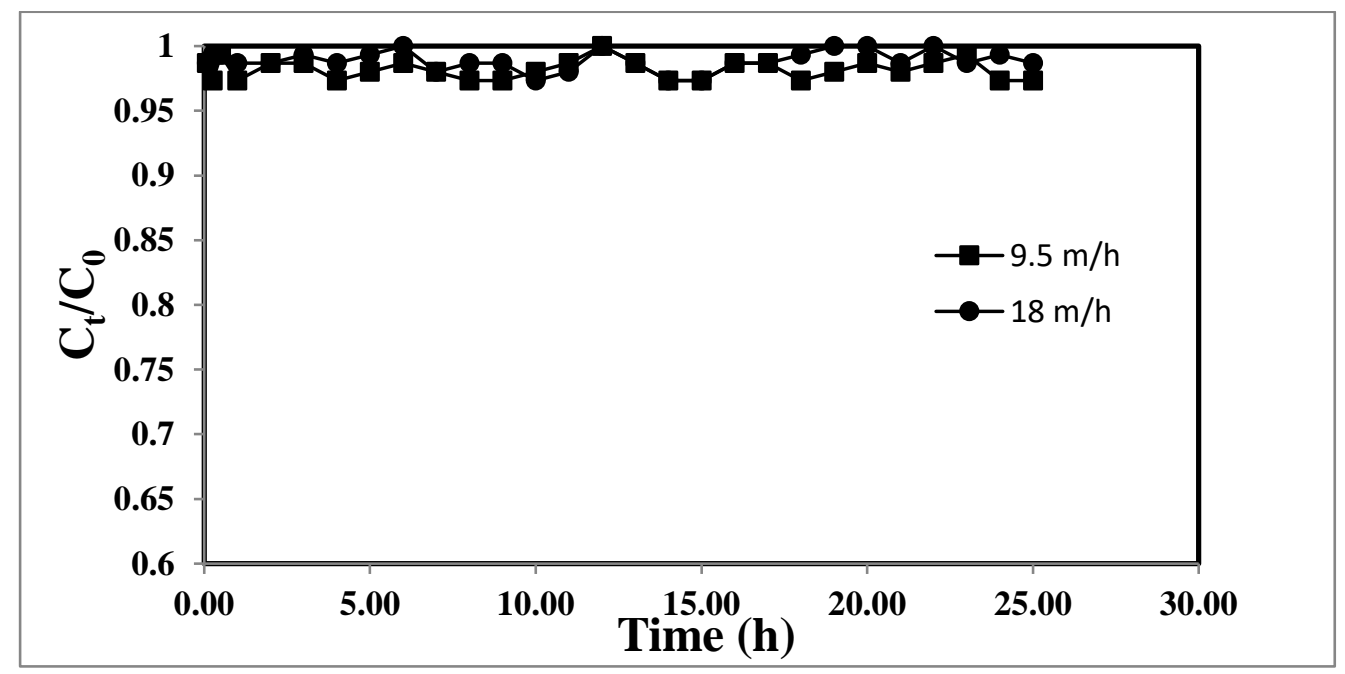

Fig. 7. Breakthrough curves for acenaphthylene adsorption on sand at two flow velocities 


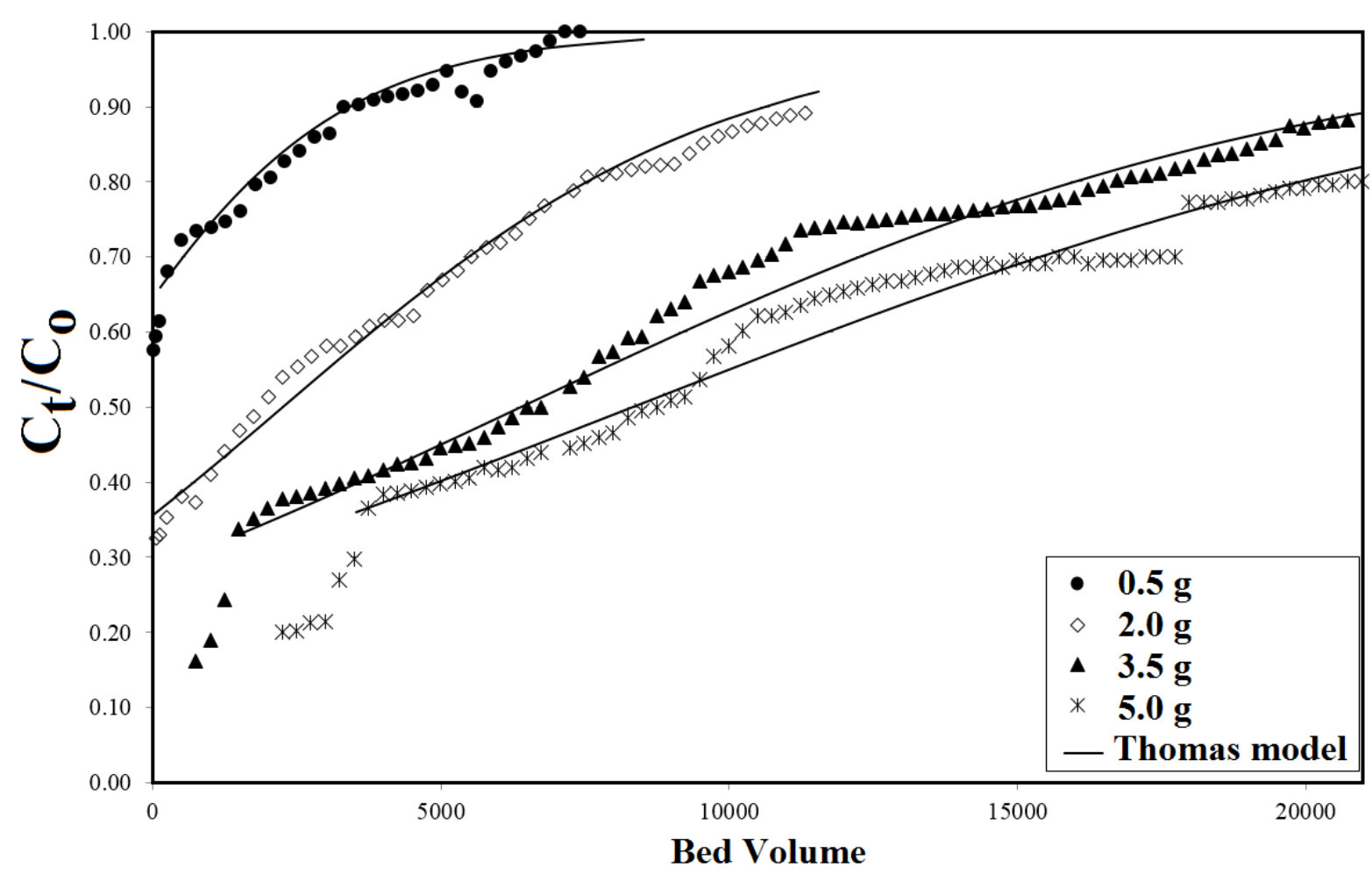

Fig. 8. Breakthrough curves for acenaphthylene adsorption at different GAC to sand ratios (weight of GAC is shown in the legend. The balance of the total weight of $25 \mathrm{~g}$ in the column was sand) and the Thomas model fits to the data.

Following the experiment with column containing sand alone, four fixed-bed column experiments were conducted for the adsorption of acenaphthylene at different weight ratios of GAC to sand in the column (Table 6). The breakthrough curves are shown in Fig. 8. As the amount of GAC in the column increased, the breakthrough curve became less steep and took longer to reach saturation point, indicating that the adsorption capacity increased. The breakthrough adsorption capacities at different times and the maximum adsorption capacities calculated manually are presented in Table 7 and 8, respectively. Although the amount adsorbed grew as GAC weight increased, the adsorption capacity expressed as amount adsorbed per unit weight of GAC remained approximately constant. The Thomas model described the data very well for the 0.5 and $2.0 \mathrm{~g}$ GAC treatments $\left(\mathrm{R}^{2}=0.962-0.989\right)$ but not so well for the 3.5 and $5.0 \mathrm{~g}$ GAC treatments, especially at low bed volumes $\left(\mathrm{R}^{2}=0.939\right.$ - 
0.940) (Table 8, Fig. 8). At low bed volumes the effluent acenaphthylene concentrations were low and are in the same order as the error in the measurement of the concentration of acenaphthylene. Therefore, at low bed volumes the measured values can demonstrate a larger deviation from the model results. For the 0.5 and $2.0 \mathrm{~g}$ data, the model results passes through the experimental data in such a way that there is an even balance between experimental data above and below the line of the model results as the effluent concentrations are high. The maximum adsorption capacities calculated from the model were not too much different from those calculated manually. 
Table 7. Breakthrough adsorption capacities at different breakthrough times for different GAC weights

\begin{tabular}{llllll}
\hline Breakthrough & Bed Volume & \multicolumn{4}{l}{ Adsorption capacities $(\mathrm{mg} / \mathrm{g})$ for different GAC weights } \\
\cline { 3 - 5 } time $(\mathrm{h})$ & & $0.5(\mathrm{~g})$ & $2(\mathrm{~g})$ & $3.5(\mathrm{~g})$ & $5(\mathrm{~g})$ \\
\hline $0-5$ & $0-1275$ & 12.1 & 6.5 & 5.1 & 4.0 \\
$5-10$ & $1275-2549$ & 8.3 & 5.1 & 4.8 & 3.5 \\
$10-15$ & $2549-3824$ & 4.8 & 4.4 & 3.6 & 3.1 \\
$15-20$ & $3824-5099$ & 3.2 & 3.8 & 3.4 & 2.6 \\
$20-25$ & $5099-6373$ & 2.6 & 3.1 & 3.2 & 2.5 \\
\hline
\end{tabular}

Table 8: Column adsorption parameters for acenaphthylene adsorption at different ratios of GAC to sand

\begin{tabular}{|c|c|c|c|c|c|}
\hline GAC & Sand & Amount & Adsorption & Thomas adsorption & Thomas \\
\hline weight & weight $(\mathrm{g})$ & adsorbed in & capacity & capacity (mg/g GAC) & model \\
\hline$(\mathrm{g})$ & & column (mg) & $(\mathrm{mg} / \mathrm{g}$ GAC) & & fit $R^{2}$ \\
\hline 0.5 & 24.5 & 15.5 & 30.9 & 23.5 & 0.962 \\
\hline 2 & 23 & 62.6 & 31.3 & 22.6 & 0.989 \\
\hline 3.5 & 21.5 & 134.7 & 38.6 & 27.5 & 0.939 \\
\hline 5 & 20 & 191.7 & 38.3 & 22.5 & 0.940 \\
\hline
\end{tabular}


Table 9. Breakthrough adsorption capacities at different times for three PAHs (GAC $0.5 \mathrm{~g}$ )

\begin{tabular}{lllll}
\hline Breakthrough & Bed Volume & \multicolumn{3}{c}{ Adsorption capacities (mg/g) } \\
\cline { 3 - 5 } time (h) & & Naphthalene & Acenaphthylene & Acenaphthene \\
\hline $0-2$ & $0-510$ & 5.0 & 5.5 & 6.0 \\
$2-4$ & $510-1020$ & 3.7 & 4.5 & 4.6 \\
$4-6$ & $1020-1530$ & 3.2 & 4.2 & 3.4 \\
$6-8$ & $1530-2039$ & 2.1 & 3.4 & 2.5 \\
$8-10$ & $2039-2549$ & 1.5 & 2.8 & 1.9 \\
$10-12$ & $2549-3059$ & 0.8 & 2.4 & 1.0 \\
$12-14$ & $3059-3569$ & 0.3 & 1.7 & 0.5 \\
\hline
\end{tabular}

The breakthrough curves for the adsorption of naphthalene, acenaphthylene and acenaphthene showed that acenaphthylene took much more time to reach column saturation than acenaphthene; acenaphthene took slightly longer than naphthalene (Fig. 9). The adsorption capacities followed the same order (Table 9). Maximum adsorption capacities (mg/g) of acenaphthylene, acenaphthene and naphthalene calculated from the breakthrough curves were 31.0, 20.0 and 16.2, respectively. These values followed the same order as the batch equilibrium adsorption capacities for these three PAHs (Table 6). The Thomas model fitted satisfactorily to the breakthrough curves $\left(\mathrm{R}^{2}=0.942-0.992\right.$, Table 10) (Fig. 8). The adsorption capacities calculated from this model for the three PAHs (Table 10) had the same trend as the Langmuir adsorption capacities obtained in the batch adsorption study (Table 6). However, the Langmuir adsorption values were much higher than the column adsorption capacities. Nguyen et al. (2015) also reported lower column values than batch values for heavy metal adsorption on zeolite and iron-coated zeolite. They offered two reasons for this: firstly, adsorption did not 
attain equilibrium in the column study in contrast to that in the batch study; and secondly, the column adsorption was calculated at lower metal concentrations in the feed solution compared to higher metal concentrations in the batch study at which Langmuir adsorption maxima were calculated.

Table 10: Column adsorption parameters for different PAHs (GAC weight (g): sand weight $(\mathrm{g})=0.5: 24.5)$

\begin{tabular}{|c|c|c|c|c|}
\hline PAH & $\begin{array}{l}\text { Amount adsorbed } \\
\text { in column (mg) }\end{array}$ & $\begin{array}{l}\text { Adsorption } \\
\text { capacity } \\
(\mathrm{mg} / \mathrm{g} \text { GAC) }\end{array}$ & $\begin{array}{l}\text { Thomas } \\
\text { adsorption capacity } \\
\text { (mg/g GAC) }\end{array}$ & $\begin{array}{l}\text { Thomas } \\
\text { model fit } \\
\mathrm{R}^{2}\end{array}$ \\
\hline Naphthalene & 8.4 & 16.2 & 12.8 & 0.942 \\
\hline Acenaphthylene & 15.5 & 31.0 & 23.6 & 0.962 \\
\hline Acenaphthene & 10.1 & 20.0 & 13.6 & 0.992 \\
\hline
\end{tabular}



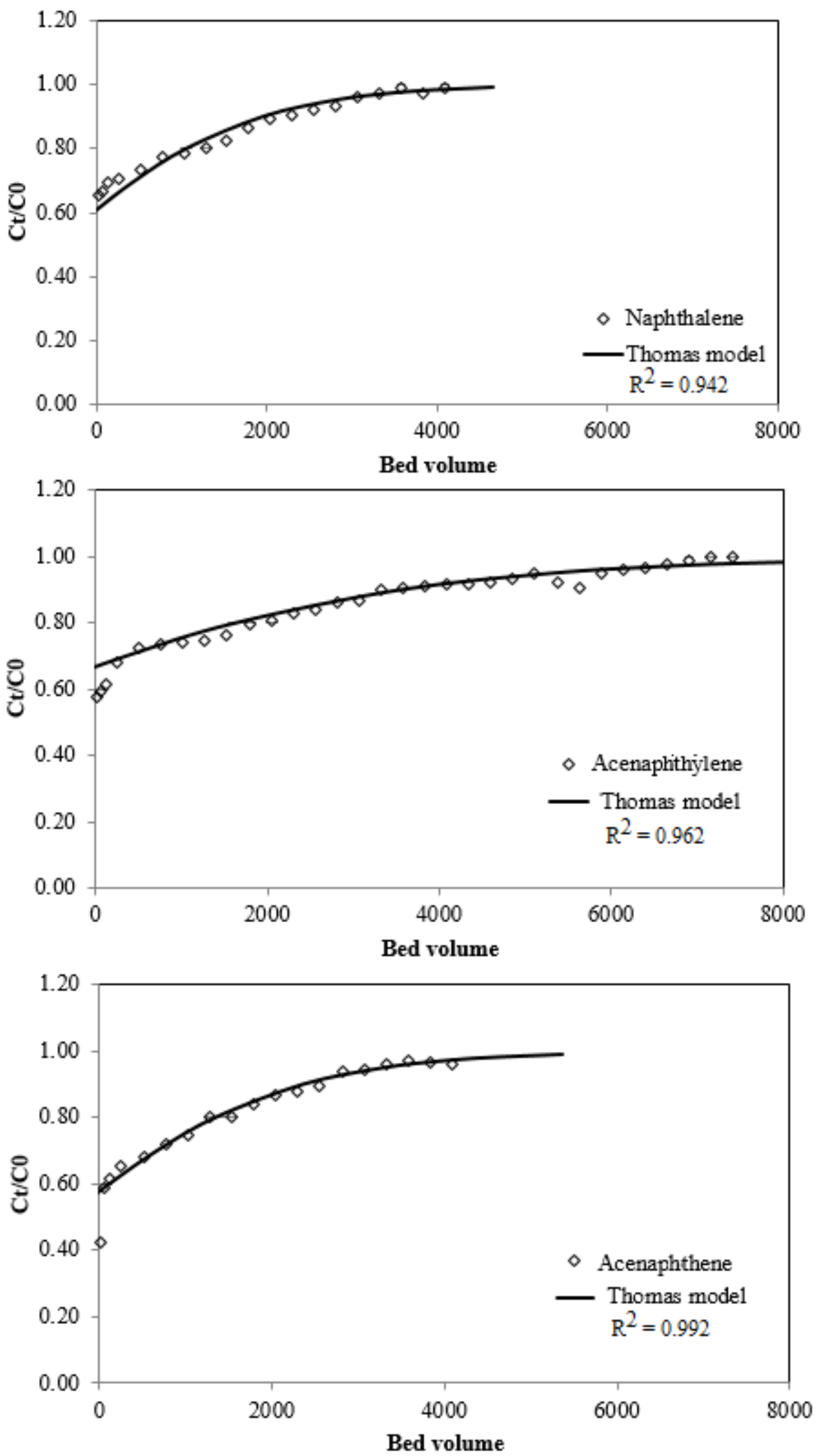

Fig. 9. Thomas model fit for the breakthrough curves of naphthalene, acenaphthene and acenaphthylene adsorption (GAC weight $(\mathrm{g})$ : sand weight $(\mathrm{g})$ in column $=0.5: 24.5)$. 


\section{Conclusions}

Batch and column adsorption experiments on five PAHs showed that GAC can effectively remove PAHs from water. Batch kinetics adsorption was satisfactorily described by the PFO, PSO, and Elovich models, with PFO being the best of the three. The Weber and Morris diffusion model produced two distinctive linear plots for the amount adsorbed vs square root of time, indicating two consecutive intra-particle diffusion rates of adsorption, probably one through the mesopores and the other through the micropores of GAC. The diffusion rates were negatively related to molar volumes of PAHs; smaller PAHs diffused faster than the larger ones.

Batch equilibrium adsorption was satisfactorily described by the Freundlich, Langmuir, and Dubinin-Radushkevich models, with the data fitting being the best to the Freundlich, indicating heterogeneous adsorption. The energy of adsorption calculated from the DubininRadushkevich model confirmed the physical nature of adsorption suggested by the PFO kinetic model. The Langmuir adsorption affinity constants for the PAHs were in the reverse order as the rates of adsorption and depended mainly on the hydrophobicity of the PAHs.

Fixed-bed columns containing $2 \%$ GAC and $98 \%$ sand by weight removed substantial amounts of PAHs. The breakthrough curves were successfully simulated by the Thomas model. The Thomas adsorption capacities had the same trend as the Langmuir adsorption capacities for the PAHs, despite the fact that the Thomas values were lower.

\section{Acknowledgement}

This study was financially supported by the Cooperative Research Centre for Contamination Assessment and Remediation of the Environment (CRC CARE) (project number 
4.1.15.12/13). We thank Dr Andrew Kinsela of the University of New South Wales, Australia for analysing GAC samples for surface area, pore size distribution and scanning electron microscopy.

\section{References}

Alade AO, Amuda OS, Ibrahim AO (2012) Isothermal studies of adsorption of acenaphthene from aqueous solution onto activated carbon produced from rice (Oryza sativa) husk. Environ Sci Technol 46:87-95

Ania CO, Cabal B, Pevida C, Arenillas A, Parra JB, Rubiera F, Pis JJ (2007) Removal of naphthalene from aqueous solution on chemically modified activated carbons. Water Res 41:333-340

Awoyemi A (2011) Understanding the adsorption of polycyclic aromatic hydrocarbons from aqueous phase onto activated carbon. Masters Dissertation, University of Toronto

Boving TB, Zhang W (2004) Removal of aqueous-phase polynuclear aromatic hydrocarbons using aspen wood fibres. Chemosphere 54:831-839

Chen BL, Zhou DD, Zhu LZ (2008) Transitional adsorption and partition of nonpolar and polar aromatic contaminants by biochars of pine needles with different pyrolytic temperatures. Environ Sci Technol 42:5137-5143

Cooney DO (1999) Adsorption design for wastewater treatment. Lewis Publishers, Boca Raton, Florida

Crisafully R, Milhome MAL, Cavalcante RM, Silveira ER, De Keukeleire D, Nascimento RF (2008) Removal of some polycyclic aromatic hydrocarbons from petrochemical 
wastewater using low-cost adsorbents of natural origin. Bioresour Technol 99:45154519

Eeshwarasinghe D, Loganathan P, Kalaruban M, Sounthararajah DP, Kandasamy J, Vigneswaran S (2017) Polycyclic aromatic hydrocarbons in water: simple analytical method and removal technique. International Conference in Waste Water and Waste Management for Extractive Industries. October 23-24, 2017, Nusa Dua, Bali, Indonesia, Book of Abstract page 68

Gustafson KE, Dickhut RM (1994) Molecular diffusivity of polycyclic aromatic hydrocarbons in aqueous solution. J Chem Eng Data 39:281-285

Haro M, Cabal B, Parra JB, Ania CO (2011) On the Adsorption Kinetics and Equilibrium of Polyaromatic Hydrocarbons from Aqueous Solution. Adsorpt Sci Technol 29:467-478

Kalaruban M, Loganathan P, Shim WG, Kandasamy J, Naidu G, Nguyen TV, Vigneswaran S (2016a) Removing nitrate from water using iron-modified Dowex 21K XLT ion exchange resin: Batch and fluidised-bed adsorption studies. Sep Purif Technol 158:6270

Kalaruban M, Loganathan P, Shim WG, Kandasamy J, Ngo HH, Vigneswaran S (2016b) Enhanced removal of nitrate from water using amine-grafted agricultural wastes. Sci Total Environ 565:503-510

Khan E, Khaodhir S, Rotwiron P (2007) Polycyclic aromatic hydrocarbon removal from water by natural fiber sorption. Water Environ Res 79:901-911

Lamichhane S, Balkrishna KC, Sarukkalige R (2016) Polycyclic aromatic hydrocarbons (PAHs) removal by sorption: A review. Chemosphere 148:336-353 
Liu L, Liu A, Li D, Zhang L, Guan Y (2016) Characterizing polycyclic aromatic hydrocarbon build-up processes on urban road surfaces. Environ Pollut 214:185-193

Long C, Lu JD, Li A, Hu D, Liu F, Zhang Q (2008) Adsorption of naphthalene onto the carbon adsorbent from waste ion exchange resin: Equilibrium and kinetic characteristics. J Hazard Mater 150: 656-661

Makkar RS, Rockne KJ (2003) Comparison of synthetic surfactants and biosurfactants in enhancing biodegradation of polycyclic aromatic hydrocarbons. Environ Toxicol Chem 22:2280-2292

Manoli E, Samara C (1999) polycyclic aromatic hydrocarbons in natural waters: sources occurrence and analysis. TrAC Trends Anal Chem 18:417-428

Miller MM, Wasik SP, Huang GL, Shiu WY, Mackay D (1985) Relationships between octanolwater partition coefficient and aqueous solubility. Environ Sci Technol 19:522-529

Naidu G, Nur T, Loganathan P, Kandasamy J, Vigneswaran S (2016) Selective sorption of rubidium by potassium cobalt hexacyanoferrate. Sep Purif Technol 163:238-246

Nemr AE, Abdelwahab O, El-Sikaily, Khaled (2009) Removal of direct blue-86 from aqueous solution by new activated carbon developed from orange peel. J Hazard mater 161:102110

Nguyen TC, Loganathan P, Nguyen TV, Vigneswaran S, Kandasamy J, Slee D, Stevenson G, Naidu R (2014). Polycyclic aromatic hydrocarbons in road-deposited sediments, water sediments, and soils in Sydney, Australia: Comparisons of concentration distribution, sources and potential toxicity. Ecotoxicol Environ Safety 104:339-348 
Nguyen TC, Loganathan P, Nguyen TC, Vigneswaran S, Kandasamy J, Naidu R (2015) Simultaneous adsorption of $\mathrm{Cd}, \mathrm{Cr}, \mathrm{Cu}, \mathrm{Pb}$, and $\mathrm{Zn}$ by an iron-coated Australian zeolite in batch and fixed-bed column studies. Chem Eng J 270:393-404

Nur T, Johir MAH, Loganathan P, Nguyen TV, Vigneswaran S, Kandasamy J (2013). Phosphate removal from water using an iron oxide impregnated strong base anion exchange resin. J Ind Eng Chem 20:1301-1307

Riahi K, Chaabane S, Thayer BB (2017) A kinetic modeling study of phosphate adsorption onto Phoenix dactylifera L. date palm fibers in batch mode. J Saudi Chem Soc 21:S143S152

Sing KSW (2004) Characterization of porous materials: past, present and future. Colloids Surface A 241:3-7

Tripathy SS, Raichur AM (2008) Abatement of fluoride from water using manganese dioxidecoated activated alumina. J Hazard Mater 153:1043-1051

Valderrama C, Cortina JL, Farran A, Gamisans X, Lao C (2007) Kinetics of sorption of polyaromatic hydrocarbons onto granular activated carbon and Macronet hyper-crosslinked polymers (MN200). J Colloid Interface Sci 310:35-46

Valderrama C, Gamisans X, De las Heras X, Farran A, Cortina JL (2008) Sorption kinetics of polycyclic aromatic hydrocarbons removal using granular activated carbon: intraparticle diffusion coefficients. J Hazard Mater 157:386-396

Valderrama C, Gamisans X, Cortina JL, Farrán A, De las Heras FX (2009) Evaluation of polyaromatic hydrocarbon removal from aqueous solutions using activated carbon and hyper-crosslinked polymer (Macronet MN200). J Chem Technol Biotechnol 84:236- 
Wammer KH, Peters CA (2006) A molecular modeling analysis of polycyclic aromatic hydrocarbon biodegradation by naphthalene dioxygenase. Environ Toxicol Chem 25:912-920

Weber WJ, Morris JC (1963) Kinetics of adsorption on carbon from solution. J Sanit Eng Div - ASCE 89:31-59

Wu X, Fan M, Mclaughlin JF, Shen X, Tan G (2018) A novel low-cost method of silica aerogel fabrication using fly ash and trona ore with ambient pressure drying technique. Powder Technol 323:310-322

Yakout SM, Daifullah AA, El-Reefy SA (2013) Adsorption of naphthalene, phenanthrene and pyrene from aqueous solution using low-cost activated carbon derived from agricultural wastes. Adsorpt Sci Technol 31:293-302

Yuan M, Tong S, Zhao S, Jia CQ (2010) Adsorption of polycyclic aromatic hydrocarbons from water using petroleum coke-derived porous carbon. J Hazard Mater 181:1115-1120

Zhang ZL, Hong HS, Zhou JL, Yu G (2004) Phase association of polycyclic aromatic hydrocarbons in the Minjiang river Estuary, China. Sci Total Environ 323:71-86 